\section{A patient's success story}

Janet Murray, a guard in a correctional facility, is a 42 year old white woman with an 8 year history of frequency, urgency, and nocturia. Before treatment, she voided up to 25 times in a 24 hour period; four to six times per night. Janet could remember experiencing only one normal night's rest after the age of 40. She was concerned that her impaired sleep was placing her job at risk because of drowsiness during the day shift and urinary frequency (aggravated by a lack of readily available lavatory access) during the night shift. She had failed bladder training, timed voiding, biofeedback, and maximum doses of anticholinergic medications, including Ditropan XL, Detrol LA, and imipramine. Urodynamics showed an unstable bladder. Luckily, Janet was deemed a candidate for a new method of neuromodulation with an implantable device called InterStim. Similar to a cardiac pacemaker but stimulating the third sacral nerve, InterStim has achieved remarkable results, with a reduction in episodes of nocturia of more than $60 \%$. One year after implantation, Janet reports having had an immediate and sustained improvement in her frequency and nocturia. She now voids a total of six to eight times in 24 hours, with no episodes of nocturia. Her job is no longer at risk, and her quality of life has improved substantially.
12 Swithinbank LV, Donovan J, James MC, Yang O, Abrams P. Female urinary symptoms: age prevalence in a community dwelling population urinary symptoms: age prevalence in a community dwelling popul
using a validated questionnaire. Neurourol Urodyn 1998;16:432.

13 Hetta J, Rimon R, Almqvist M. Mood alterations and sleep. Ann Clin Res 1985;17:252.

14 Lindberg E, Janson C, Gislason T, Bjornsson E, Hetta J, Boman G. Sleep disturbances in a young adult population: can gender differences by explained by differences in psychological status? Sleep 1997;20:381.

15 Saito M, Kondo A, Kato T, Yamada Y. Frequency-volume charts: comparison of frequency between elderly and adult patients. Br J Urol 1993;72:38

16 Weiss JP, Blaivas JG, Stember DS. Nocturia in adults: etiology and classification. Neurourol Urodyn 1998;17:467.

17 Weiss JP, Blaivas JG. Nocturia. J Urol 2000;163:5-12.

18 Krieger J, Petiau C, Sforza E, Delanoe C, Hecht MT Chamouard V. NocKrieger J, Petiau C, Storza E, Delanoe C, Hecht MT, Chamouard V. Noc-
turnal pollakiuria is a symptom of obstructive sleep apnea. Urol Int turnal pollak

19 Pederson PA, Johansen PB. Prophylactic treatment of adult nocturia with bumetanide. BrJ Urol 1988;62:145.

20 Hunsballe JM, Rittig S, Pedersen EB, Olesen OV, Djurhuus JC. Single dose imipramine reduces nocturnal urine output in patients with nocturnal enuresis and nocturnal polyuria. J Urol 1997;158:830.

21 Drake MJ, Mills IW, Noble JG. Melatonin pharmacotherapy for nocturia in men with benign prostatic enlargement. J Urol 2004;171:1199-202.

22 Hassouna MM, Siegel SW, Nyeholt AA, Elhilali MM, van Kerrebroeck PE, Das AK, et al. Sacral neuromodulation in the treatment of urgency-frequency symptoms: a multicenter study on efficacy and safety. Urol 2000;163:1849-54.

23 Spinelli M, Giardiello G, Gerber M, Arduini A, van den Hombergh U, Spinelli M, Giardiello G, Gerber M, Arduini A, van den Hombergh U,
Malaguti S. New sacral neuromodulation lead for percutaneous implantation using local anesthesia: description and first experience. $J$ Uro 2003;170:1905-7

24 Medtronic. What is InterStim therapy? www.interstim.com (accessed 31 Mar 2004).

(Accepted 9 March 2004) device with a neuromodulation unit only slightly larger than a pager attached to the patient's regular pant belt. This stage 1 procedure is performed under local anaesthesia and takes less than 45 minutes. If the patient's symptoms improve by more than $50 \%$, a permanent device is implanted in either buttock with a $6 \mathrm{~cm}$ incision. The device can be programmed via an extracorporeal handheld device for increases or decreases in power magnitude. The effects on nocturia have been remarkable, with a reduction of more than $60 \%$ in episodes of nocturia, even in patients taking diuretic medication. Adverse events such as pain at the implant site, lead migration, infection or skin irritation, or technical or device related problems are possible in up to one third of patients, and contraindications such as benign prostatic hypertrophy, cancer, or urethral stricture may exclude some patients from candidacy for the procedure ${ }^{24}$; in general, however, sacral neuromodulation is an effective, safe, and reversible treatment and offers an important new option ${ }^{22}$ for patients with symptoms of urgency, urge incontinence, and nocturia.

Contributors: SPM and SLS authored the paper. LS edited and created figures 1 and 2. SPM is the guarantor.

Funding: None.

Competing interests: None declared.

1 Middlekoop HA, Smilde-van den Doel DA, Neven AK, Kamphuisen HA, Springer CP. Subjective sleep characteristics of 1,485 males and females aged 50-93: effects of sex and age, and factors related to self-evaluated quality of sleep.J Gerontol 1996;51:M108.

2 Asplund R, Aberg HE. Micturition habits of older people. Voiding frequency and urine volumes. Scand J Urol Nephrol 1992;26:345.

3 Shah PJR. The assessment of patients with a view to urodynamics. Urodynam ics: principles, practice and application. New York: Churchill Livingstone, 1994.

4 Hennessy CH, Shen JKM. Sources of unreliability in the multidisciplinary team assessment of the elderly. Eval Rev 1986;10:178.

5 Umlauf MG, Goode S, Burgio K. Psychosocial issues in geriatric urology: problems in treatment and treatment seeking. Urol Clin North Am 1996;23:127

6 Fultz NH, Herzog AR. Epidemiology of urinary symptoms in the geriatric population. Urol Clin North Am 1996;23:1

7 Barker JC, Mitteness LS. Nocturia in the elderly. Gerontologist 1988;28:99.

8 Matthiesen TB, Rittig S, Norgaard JP, Pedersen EB, Djurhuus JC. Nocturnal polyuria and natriuresis in male patients with nocturia and lower urinary tract symptoms.J Urol 1996;156:1292.

9 Sullivan MP, Yalla SV. Alternate methods in the treatment of benign prostatic hyperplasia. New York: Springer, 1993.

10 Broman JE, Lundh LG, Hetta J. Insufficient sleep in the general populaBroman JE, Lundh LG, Hetta J. In
tion. Neurophysiol Clin 1996;26:30.

11 Jolleys JV, Donovan JL, Nanchahal K, Peters TJ, Abrams P. Urinary symptoms in the community: how bothersome are they? BrJ Urol 1994;74:551.

\section{Corrections and clarifications}

Minimally invasive parathyroidectomy

Late insertion of authors' affiliations in this editorial led to some confusion over authorship, which resulted in us adding a third, non-existent, author, T S Reene (10 April, pp 849-50). The article had only two authors, F Fausto Palazzo and Gregory P Sadler, both of whom worked at John Radcliffe Hospital in Oxford (as specialist registrar in endocrine surgery and consultant endocrine surgeon respectively) at the time of writing the editorial. F Fausto Palazzo is now T S Reeve fellow in endocrine surgery, Royal North Shore Hospital, Sydney, Australia. The authorship has been amended on bmj.com.

Why do doctors use treatments that do not work? The authors of this editorial, Jenny Doust and Chris Del Mar, prompted by a rapid response, have alerted us to an error in their editorial (28 February, pp 474-5). In the fourth paragraph, they misquoted reference 9 . The authors had written that flecainide for the treatment of supraventricular tachycardia makes the electrocardiogram look normal, whereas the trial cited investigated use of flecainide for ventricular tachycardia.

This week in the BMJ: Three days of amoxicillin are enough for non-severe pneumonia

We inadvertently omitted the word "excess" in this summary paragraph for the paper by the ISCAP Study Group ("Three day versus five day treatment with amoxicillin for non-severe pneumonia in young children: a multicentre randomised controlled trial," 3 April, pp 791-4). The fourth sentence should read: "Clinical failure was more likely with non-adherence to treatment at day 5 , an excess respiratory rate of $>10$ breaths/minute, and infection with respiratory syncytial virus." Although the reader who alerted us to this error claimed that the slip prompted him to read the whole article, introducing errors to attract readers is not a strategy that we are planning to adopt. 